\title{
Confirmation of prenatal diagnosis of cystic fibrosis by DNA typing of fetal tissues
}

\author{
ANN CURTIS, LISA STRAIN, MOIRA MENNIE, AND DAVID J H BROCK \\ From the Human Genetics Unit, University of Edinburgh, Western General Hospital, Edinburgh EH4 $2 X U$.
}

SUMMARY Tissues from eight fetuses, diagnosed on the basis of amniotic fluid microvillar enzyme assay as having cystic fibrosis, were conserved in frozen storage for up to three years. Adequate samples of undegraded DNA could be extracted from small intestine, lung, and liver. DNA typing, with restriction fragment length polymorphisms tightly linked to the cystic fibrosis gene, showed all eight diagnoses to have been correct. Determining the DNA genotype of fetal material can also be used to establish the linkage relationship between markers and the cystic fibrosis gene, and will permit subsequent first trimester prenatal diagnosis for couples who have no living affected child.

For the past three years ${ }^{1}$ measurement of amniotic fluid microvillar enzyme activities has been used for prospective second trimester prenatal diagnosis of cystic fibrosis (CF). Most mothers with abnormally low enzyme activities signalling an affected fetus have chosen termination of pregnancy. It is possible to confirm the diagnosis of $\mathrm{CF}$ in the fetus by analysis of the biochemistry of the fetal meconium, ${ }^{2}{ }^{3}$ but hitherto there has been no independent way of verifying that abnormal fetal meconium correctly indicates a $\mathrm{CF}$ fetus.

The discovery of restriction fragment length polymorphisms (RFLPs) tightly linked to the CF gene $^{45}$ has now made first trimester prenatal diagnosis of CF possible. ${ }^{6}$ Since recombination between the DNA markers $(\mathrm{pJ} 3 \cdot 11$, met $\mathrm{H}$, and met D) and the CF gene is very rare, ${ }^{7}$ such diagnoses have high predictive accuracy. We have therefore used DNA typing on fetal tissue in an attempt to confirm diagnoses originally based on microvillar enzyme testing. Such typing also permits a subsequent first trimester prenatal diagnosis to be made even when a couple has no living affected child.

\section{Materials and methods}

At the start of this study it was anticipated that some of the microvillar enzyme based diagnoses might turn out to be false positives. Blood samples were therefore only requested from those couples who were contemplating further pregnancies and who would benefit from knowing whether they were informative for DNA based prenatal diagnosis. The criteria for inclusion of the seven families in the study were: (1) fetal tissues had been conserved from a second trimester fetus, (2) there was a living index affected child, and (3) blood samples were available from both parents and from the affected child. In one family fetal tissues from two consecutive pregnancies were analysed.

Fetal tissues were thawed and genomic DNA extracted by the method of Marshall and Burgoyne. ${ }^{8}$ DNA was isolated from the white cell fraction of whole blood by standard methods. The anonymous probes $\mathrm{pJ} 3 \cdot 11^{5}$ and $7 \mathrm{c} 22^{9}$ and the two genomic probes at the met oncogene locus, ${ }^{4}$ met $\mathrm{H}$ and met $\mathrm{D}$, were used as described.

\section{Results}

Storage times and yields of DNA are shown in table 1 for the different fetal tissues extracted. Agarose gel electrophoresis followed by ethidium bromide staining confirmed that the DNA was of high molecular weight and essentially undegraded despite the long storage times.

DNA genotypes for the seven families are shown in table 2 . The simplest is family 1 where homozygosity for both the $2.3 \mathrm{~kb}$ met $\mathrm{H}-\mathrm{MspI}$ allele and the $1 \cdot 8 \mathrm{~kb} \mathrm{pJ} 3 \cdot 11-M s p I$ allele in the index affected child makes prediction of fetal CF possible on each marker. The figure illustrates the pedigree of this family and the band patterns for the met $\mathrm{H}-\mathrm{MspI}$ system, showing the fetal genotype to be identical to that of the index affected child. In this family the unaffected sib is a heterozygote. 
TABLE 1 Yield of DNA from stored fetal tissue.

\begin{tabular}{llll}
\hline Family & Tissue & $\begin{array}{l}\text { Yield } \\
(\mathrm{mg} / \mathrm{g} \text { wet tissue })\end{array}$ & $\begin{array}{l}\text { Storage time } \\
\text { (months) }\end{array}$ \\
\hline & Small intestine & 1.03 & \\
1 & Small intestine & 0.50 & 18 \\
2 & Small intestine & 0.59 & 16 \\
3 & Liver & 1.40 & 10 \\
& Lung & 1.17 & 6 \\
4 & Liver & 1.27 & 34 \\
5 & Small intestine & 1.22 & 20 \\
$6 \mathrm{a}^{*}$ & Small intestine & 5.00 & 6 \\
$6 \mathrm{~b}^{*}$ & Small intestine & 3.75 & 8 \\
7 & Small intestine & 1.30 & \\
\hline
\end{tabular}

*Two separate pregnancies analysed from this family.

In families 2 to 7 the diagnosis of fetal CF was confirmed by analysis of at least two segregating markers. For example, in family 2 neither the met H-MspI nor the met H-TaqI systems were fully informative on their own, but when used in combination they established a unique genotype for the index affected child which was repeated in the fetus. In families 4 and 5 it was necessary to use the 7 c22-EcoRI system as well as one of the other systems to confirm the diagnosis.
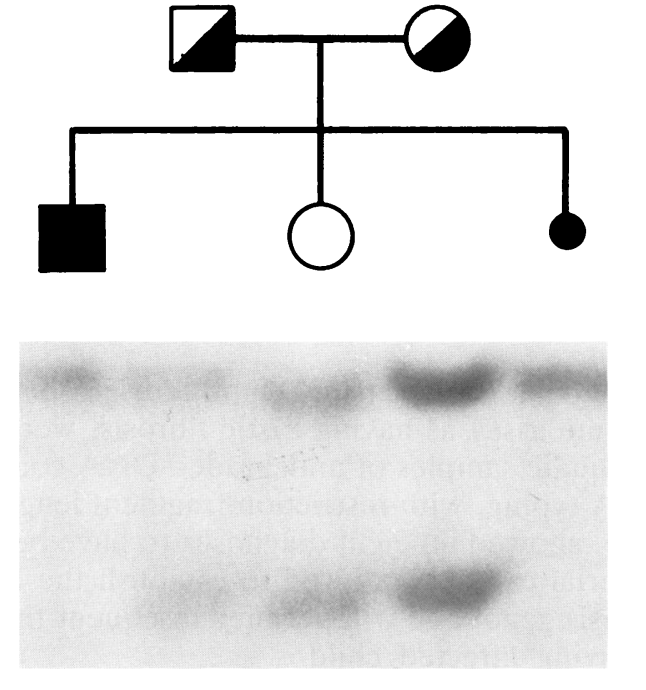

\section{MspI / met $\mathrm{H}$}

FIGURE Pedigree of family 1 with met $H$-MspI band patterns under the different subjects. From left to right: affected child, father, unaffected child, mother, fetus.

TABLE 2 DNA genotypes for the seven families.

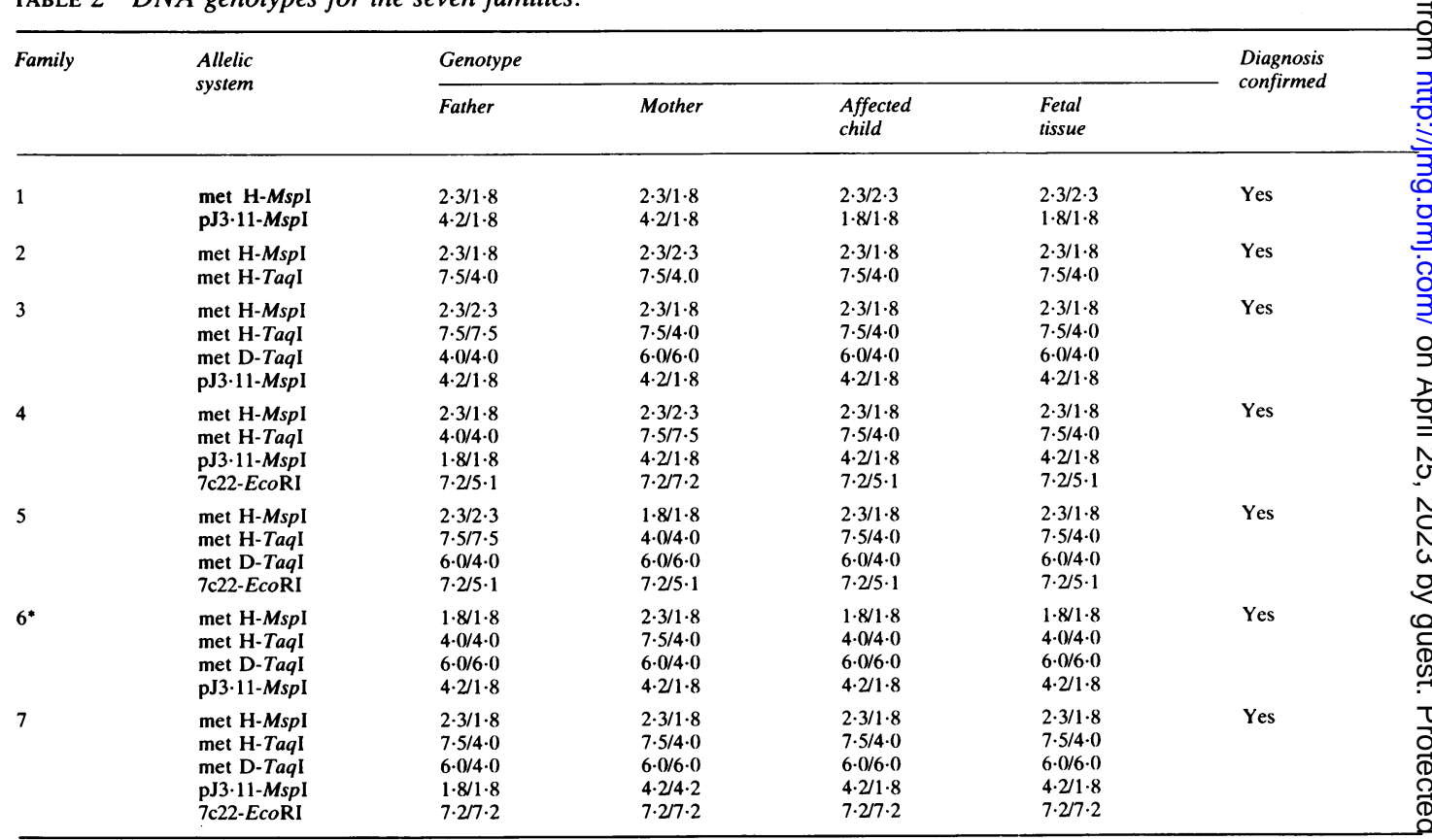

*In family 6 , both sets of fetal tissue had identical genotypes. 


\section{Discussion}

The primary objective of this study was to investigate whether DNA typing of fetal tissues from a second trimester abortus could be used to confirm a diagnosis of CF which was originally based on amniotic fluid microvillar enzyme activities. DNA typing depends on the analysis of RFLPs cosegregating with the CF gene, and it is therefore usually necessary to have blood samples from the father, the mother, and an index affected child in order to establish the phase relationships of the markers. It is estimated that in about $80 \%$ of families the use of the probes $\mathrm{pJ} 3 \cdot 11$, met $\mathrm{H}$, and met $\mathrm{D}$ will allow a diagnosis of $\mathrm{CF}$ to be made. ${ }^{6}$

We have been able to acquire the appropriate blood samples from seven families where one or more second trimester terminations of pregnancy had been carried out. In all of these, the band patterns of father, mother, and index affected child were fully informative, and therefore the unique genotype of the index affected child should have been repeated in the abortus tissues.

Adequate extracts of undegraded DNA were obtained from all eight sets of fetal tissues. This is surprising in view of the fact that a majority of samples extracted were small intestine, a tissue thought to be prone to autolytic degradation. All the samples had been stored frozen for long periods of time (up to three years), and in no case had any special precautions been taken to preserve the DNA. Tissues were not frozen until several hours after expulsion of the fetus and were then kept at $-20^{\circ} \mathrm{C}$ rather than at lower temperatures. This suggests that such tissue DNA is relatively stable and that the methods for confirmation of diagnosis described here can be used on other frozen samples.

In all eight sets of fetal tissue the microvillar enzyme based diagnosis of CF was confirmed by DNA typing.

For many couples seeking prenatal diagnosis of $\mathrm{CF}$, the early death of an index affected child precludes the use of DNA markers on a first trimester chorionic villus sample (CVS). Such couples may opt for second trimester amniocentesis and microvillar enzyme diagnosis. If the fetus is deemed to be affected and termination of pregnancy carried out, DNA typing of fetal tissues could be used to establish the genotype of a putative $\mathrm{CF}$ homozygote and the couple offered a first trimester diagnosis in subsequent pregnancies. We have shown that there are no technical obstacles to this course of action.

There is, however, likely to be some error associated with the use of such fetal tissues in establishing the phase relationships of DNA markers. The largest component of the error arises from the fact that false positive diagnoses are possible using microvillar enzyme assay for the detection of fetal CF. The magnitude of the false positive rate is difficult to ascertain. At the Seventh International Congress on Human Genetics in September 1986, a collection of world wide experience of microvillar enzyme testing identified 10 false positives in 281 pregnancies $(2 \cdot 8 \%) .{ }^{10}$ However, since most positive diagnoses are followed by termination of pregnancy, and since the validity of confirmation of diagnosis by examination of fetal meconium biochemistry cannot be rigorously tested, this is probably an underestimate. In support of this conclusion is the fact that the collected experience showed positive diagnoses being made in $29.2 \%$ of 1 in 4 risk pregnancies, significantly different from the $25 \%$ expected. This argues for a false positive rate of about $7 \%$, if a false negative rate of $5 \%$ is assumed.

Even if the false positive rate in microvillar enzyme diagnoses were to be as high as $10 \%$, there is merit in continuing to carry out DNA typing on fetal tissues. If fetal typing leads to erroneous establishment of phase relationships between DNA markers and the CF gene (because the fetus is a 'false positive'), only half of the subsequent diagnoses will be wrong, and only one quarter will lead to the birth of an affected child. Thus, the false positive rate will be reduced from $10 \%$ to $2 \cdot 5 \%$. The advantages to mothers of a first trimester prenatal diagnosis are so great that this is probably an acceptable error rate.

We thank Professor R Williamson for providing the probes $\mathrm{pJ} 3 \cdot 11$, met $\mathrm{H}$, and met $\mathrm{D}$ and for generous advice on technical aspects of their use; and Drs V van Heyningen, D Aitken, $R$ Wilson, I Young, and $\mathrm{J}$ Burn for help with acquisition of tissue materials. The study was supported by the Cystic Fibrosis Research Trust and the Medical Research Council.

\footnotetext{
References

1 Brock DJH. Amniotic fluid alkaline phosphatase isoenzymes in the early prenatal diagnosis of cystic fibrosis. Lancet 1983;ii:941-3.

2 Brock DJH, Bedgood D, Barron L, Hayward C. Prospective prenatal diagnosis of cystic fibrosis. Lancet 1985;i:1175-8.

3 Brock DJH, Barron L. Biochemical analysis of meconium in fetuses presumed to have cystic fibrosis. Prenat Diagn 1986;6:291-8.

4 White R, Woodward S, Leppart M, et al. A closely linked genetic marker for cystic fibrosis. Nature 1985;318:382-4.

5 Wainwright BJ, Scambler PJ, Schmidtke J, et al. Localisation of the cystic fibrosis locus to human chromosome 7cen-q22. Nature 1985;318:384-5.

${ }^{6}$ Farrall M, Law HY, Rodeck CH, et al. First-trimester prenatal diagnosis of cystic fibrosis with linked DNA probes. Lancet 1986;i:1402-5.
} 
${ }^{7}$ Beaudet A, Bowcock A, Buchwald M, et al. Linkage of cystic fibrosis to two tightly linked DNA markers: joint report from a collaborative study. Am J Hum Genet 1986;39:681-93.

${ }^{8}$ Marshall AJ, Burgoyne LA. Interpretation of the properties of chromatin extracts from mammalian nuclei. Nucleic Acids Res 1976;3:1101-10.

9 Scambler PJ, Wainwright BJ, Watson E, et al. Isolation of a further anonymous informative DNA sequence from chromosome 7 closely linked to cystic fibrosis. Nucleic Acids Res 1986;4:1951-6.
10 Brock DJH. Workshop: prenatal diagnosis of cystic fibrosis. In Vogel FG, et al, eds. Proceedings of the Seventh Internationd Congress on Human Genetics, Berlin. Berlin: Springer Verla (in press).

Correspondence and requests for reprints to $\operatorname{Dr}$ Curtis, Human Genetics Unit, Western Gener/क Hospital, Edinburgh EH4 2XU. 